\title{
CHESTNUT LAMPREY AT ROUND LAKE, 1980
}

RON JENSEN, 1027 King Crescent, Saskatoon, Saskatchewan, S7K 0N9.

Lampreys have been collected on three occasions in Saskatchewan. The most recent one was taken during the Saskatchewan Natural History annual summer meeting at McKay Camp on Round Lake in the Qu'Appelle Valley.

In June 1980, Hugh McLaughlin and Ron Jensen arranged a seining demonstration for those attending the summer meeting. The demonstration took place on the downstream side of the Round Lake control structure in a small pool. A single pull produced eight species of fish: common white sucker, northern pike, burbot, spottail shiner, emerald shiner, johnny darter, lowa darter, and chestnut lamprey.

Two previous specimens of the chestnut lamprey were collected at the Round Lake control structure in 1965 and at the dam on the
Whitesand River near Canora. These were 14.1 and $11.8 \mathrm{~cm}$ long, respectively. This third chestnut lamprey measured $15.3 \mathrm{~cm}$ in length. The specimens mentioned are in the possession of the Fisheries Research Laboratory in Saskatoon.

The chestnut, lamprey (Ichthyomyzon castaneus), a member of the Petromyzontidae family, is a small parasitic lamprey with a cylindrical body, single dorsal fin, and an oral sucking disc armed with teeth. Predominantly a stream dweller, the young chestnut lamprey or ammocoete (larvae) prefers moderate current, stable bottom of sand or silt, and a little growth of Chara. The ammocoete's life span is presumably 5-7 years, metamorphosis to an adult occurs in the fall of the last year. It is as an adult during the fall that this lamprey is parasitic, overwintering in

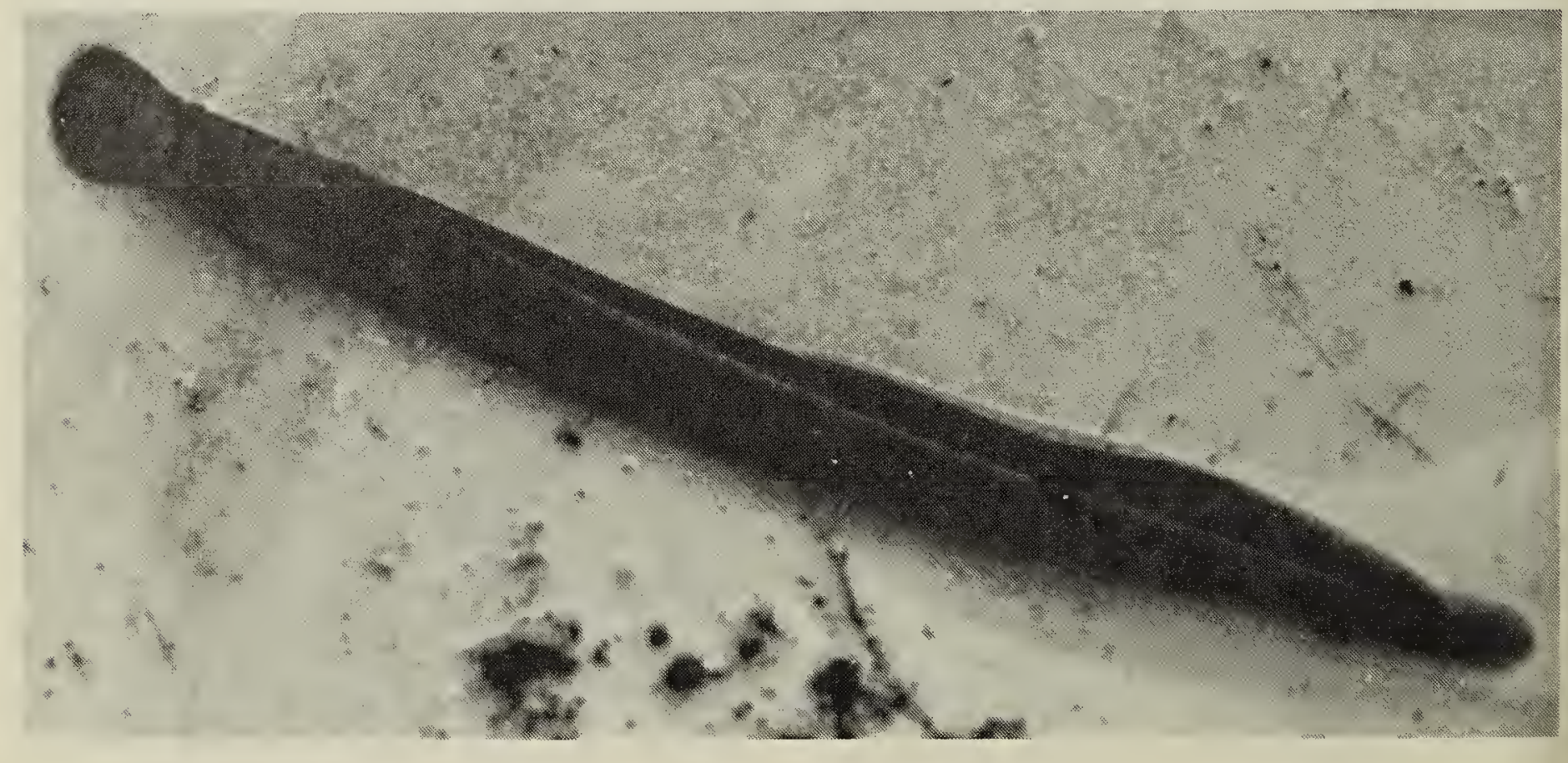




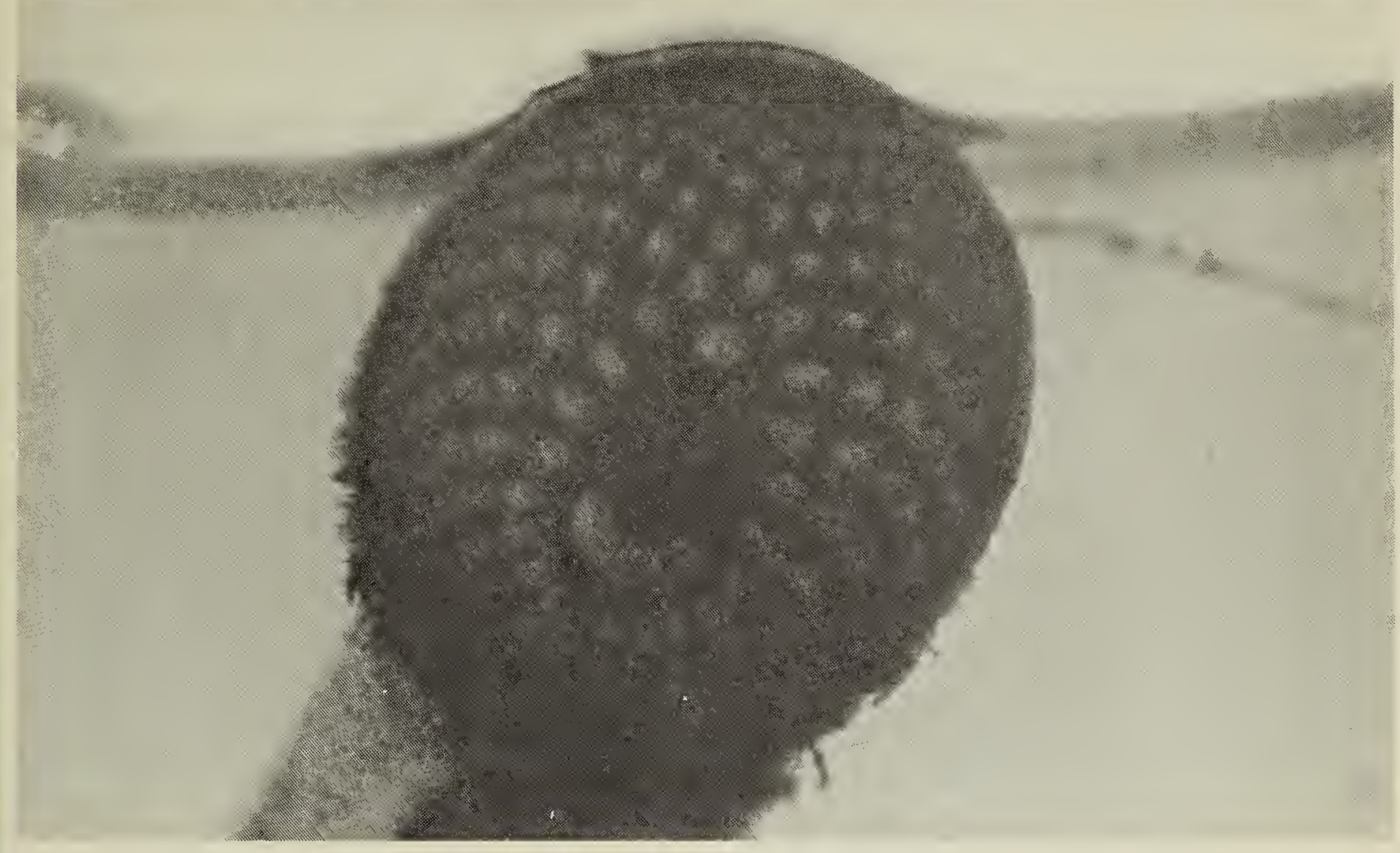

an inactive state to spawn in June or July of the following year, after which adults die.

Distribution in Canada, according to the map in Scott and Crossman, is in southeastern Manitoba. ${ }^{1}$ Ernest Seton Thompson recorded this species from the Assiniboine River in 1898.
I would like to thank Mr. Hugh McLaughlin who was the driving force for the seining demonstration.

'SCOTT, W. B. and E. J. CROSSMAN, 1973. Freshwater Fishes of Canada. Fisheries Research Board of Canada. Ottawa.

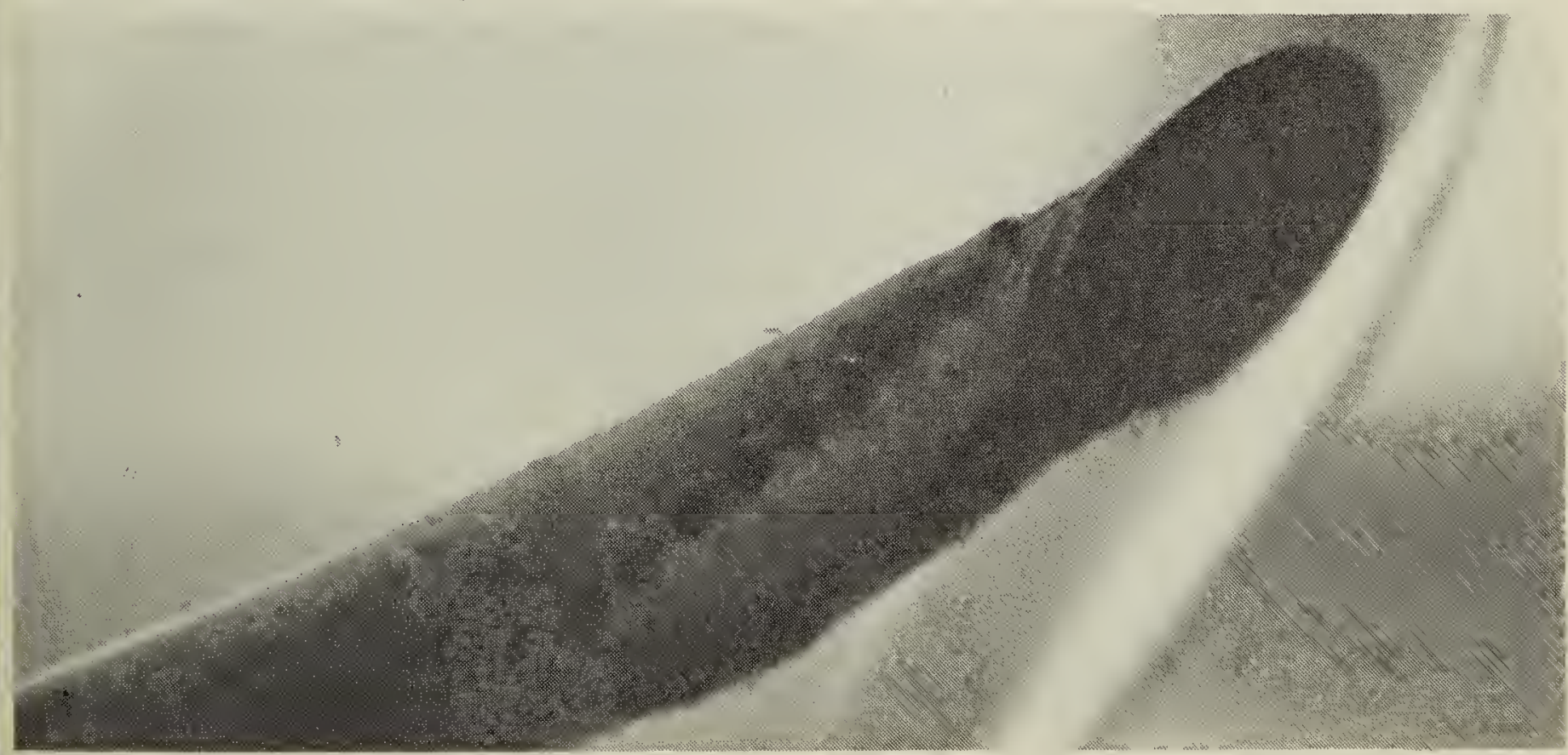

